\title{
The Design through the screens: The adaptations of interior design elaborated for Social Media
}

\author{
Keywords \\ Visual Design, Interior Design, Scenography, Social Media, Selfie, Instagramable Spaces.
}

In the Covid-19 Pandemics, the virtual world has become even more popular amongst people and companies, with the intent to maintain connections that social distancing inhibited. In this scenario, virtual commerce and digital influencers invested even further in what is known in the commercial architecture and design sphere as "Instagramable". Environments, foods, clothes, objects, everything has needed to draw attention in the social media and for that, people appeal to "Instagram-able" features, i.e., something that is photographically interesting, that incites desire, empathy, and dreaming. However, this subject is little studied in academia yet, since the articulation of elements and spaces destined for social network dissemination still does not have a solid theoretical development, for it is a recent theme. From a practical observation of spaces that have this denomination as their main characteristic, this paper begins to elaborate on an academically acceptable concept for this trend that is likely to settle in the market due to the constant rising of digital media in society. If we observe a physical environment made for residential or commercial purposes or other daily needs, we will find in the usage of thermal and acoustic comfort features, ergonomics, lighting, and functionality. However, when we label an environment "Instagram-able" or when we analyze stages that are prepared and dedicated to social media photography, we identify other characteristics, more suited to digital image propagation and bi-dimensional visualization of such spaces. There is, therefore, a certain aesthetic aspect standard that spaces that are directed mostly at social media content creation, such as "Instagram-able spaces" or selfie museums (places made with scenarios suited for taking self-portraits), follow as a means to attract people to visit and take photos to be shared in social networks. But what makes a place attractive to be displayed online? Which features lead people to photograph certain places? This paper identifies interior design features common to this kind of ambiance, focused on selfie museums found around the world. For this, a survey of museum selfies located through its main communication branch, Instagram, was carried out so far, 32 (thirtytwo) of these models have been found around the world, so that we can establish a taxonomy of what is considered "Instagram-able" for the commercial area, in an analysis of colors, themes, elements, psychodynamics, and senses that are capable of attracting and leading a person to the act of photographing themselves in that environment, and so, after this practical research, with a theoretical deepening, where it will be A multidisciplinary connection to design was analyzed to establish the concept and guidelines of what is an "Instagram-able" space for the academia environment, making this a grounded and regulated proposal for the more assertive use of designers and architects in environments that have sales interest, whether of products or of the image. 